\title{
Envelhecimento acelerado na avaliação da qualidade fisiológia de sementes de Dalbergia nigra (Vell.) Fr. All
}

\section{Accelerated aging in evaluating the quality of seed physiology of Dalbergia nigra (Vell.) Fr. All}

\author{
Roberta Sales Guedes ${ }^{1 *}$; Edna Ursulino Alves²; Lamartine Soares Bezerra \\ de Oliveira ${ }^{3}$; Leonaldo Alves de Andrade²; Edilma Pereira Gonçalves ${ }^{4}$; Paulo \\ Alexandre Rodrigues Fernandes de $\mathrm{Melo}^{5}$
}

\section{Resumo}

\begin{abstract}
O teste de envelhecimento acelerado é uma alternativa para avaliação do vigor de sementes, entretanto não há informações suficientes sobre sua eficiência para sementes florestais, como as de Dalbergia nigra (Vell.) Fr. All. (jacarandá-da-bahia). Foi conduzido experimento no Laboratório de Análise de Sementes, da Universidade Federal da Paraíba, com o objetivo de avaliar a qualidade fisiologia de sementes de D. nigra por meio do teste de envelhecimento acelerado. O teste foi conduzido a $41 \mathrm{e} 45^{\circ} \mathrm{C}$ durante 24, 48, 72 e 96 horas, além da testemunha (sementes não envelhecidas). Realizou-se o teste de emergência das plântulas em campo, para verificar a qualidade fisiológica das sementes. As sementes foram distribuídas em camada única sobre tela, em caixas plásticas com $40 \mathrm{~mL}$ de água destilada, no interior de câmara BOD. O teor de água e a germinação o vigor das sementes foram determinados antes e após o envelhecimento. $\mathrm{O}$ envelhecimento em ambas as temperaturas $\left(41^{\circ} \mathrm{C}\right.$ e $\left.45^{\circ} \mathrm{C}\right)$ a partir de 72 horas, afeta a qualidade fisiológica de sementes de Dalbergia nigra (Vell.) Fr. All., promovendo redução da viabilidade e do vigor.
\end{abstract}

Palavras-chave: Germinação. Jacarandá-da-bahia. Emergência. Vigor. Análise de sementes.

\begin{abstract}
The accelerated aging test is a possible option for evaluation of seeds vigor, however there is not enough information on your efficiency for forest seeds, as of Dalbergia nigra (Vell.) Fr. All. This study was conducted to investigate procedures to assess seed vigor by the accelerated aging test in seed forest, of Dalbergia nigra. For so much, an experiment was realized at Laboratory of Analysis of Seeds, in Universidad Federal of Paraíba, in Areia - PB, Brazil Northeast. Accelerated aging was performed at $41{ }^{\circ} \mathrm{C}$ during $24,48,72$ and 96 hours. Seeds were kept in plastic boxes with $40 \mathrm{~mL}$ of distilled water in a B.O.D chamber. Seeds were tested for germination and moisture content before and after aging. The aging at both temperatures $\left(41^{\circ} \mathrm{C}\right.$ and $\left.45^{\circ} \mathrm{C}\right)$ after 72 hours, affect the physiological quality of seeds of Dalbergia nigra (Vell.) Fr All., promoting reduction of viability and vigor.
\end{abstract}

Key words: Germination. Jacarandá-da-bahia. Vigor. Emergence. Seeds analysis.

\footnotetext{
1 Bióloga, Doutoranda do Curso de Pós-graduação em Agronomia, Depto. de Fitotecnia, CCA,Universidade Federal da Paraíba, UFPB; Areia, PB. E-mail: roberta biologa09@yahoo.com.br

2 Profa. Adjunta do Depto. de Fitotecnia, CCA, UFPB. E-mail: ednaursulino@cca.ufpb.br

3 Mestrando em Ciências Florestais, Universidade Federal Rural de Pernambuco, UFRPE. E-mail: soareslt@hotmail.com

4 Prof ${ }^{a}$ Adjunta da UAG, UFRPE. E-mail: edilma@uag.ufrpe.br

5 Aluno de Graduação em Agronomia Depto. de Fitotecnia, CCA-UFPB. E-mail: paulo.sementes@hotmail.com

* Autor para correspondência
} 


\section{Introdução}

Para a grande maioria das espécies nativas ainda são incipientes os trabalhos sobre o método de propagação. Portanto, torna-se urgente e necessário estudos sobre a qualidade fisiológica de suas sementes, visando subsidiar formação de mudas para plantios racionais e a revegetação de áreas de extrativismo e preservação ambiental. A espécie Dalbergia nigra (Vell.) Fr. All. pertence a família Fabaceae e é conhecida popularmente como jacarandá-da-bahia, jacarandá-preto ou caviúna, que se destaca por sua considerável importância econômica (CARVALHO, 1994; LORENZI, 2002). A exploração indiscriminada dessa espécie, para uso madeireiro, além da devastação de seu ambiente natural, ocasionou sua inclusão na lista de espécies da flora brasileira ameaçadas de extinção (IBAMA, 2008).

A utilização de sementes de qualidade constitui-se em fator determinante para o êxito do empreendimento florestal (GONÇALVES et al., 2009), e rotineiramente, nos laboratórios, esta qualidade tem sido analisada por meio do teste de germinação, que é o único indicativo oficial de potencial fisiológico. Entretanto, esse teste é realizado em condições favoráveis de umidade, temperatura e substrato, permitindo que as sementes do lote expressem sua máxima germinação, de forma que esse teste tem pouca eficiência para estimar o desempenho no campo, onde as condições nem sempre são favoráveis. Desta forma, os resultados de emergência das plântulas em campo podem ser consideravelmente inferiores aos obtidos no teste de germinação realizado em laboratório.

Os testes de vigor possibilitam identificar os lotes com maior ou menor probabilidade de expressar seu comportamento no campo ou durante o armazenamento. Sendo o objetivo essencial dos testes de vigor verificar diferenças importantes no potencial fisiológico entre lotes de sementes, especialmente daqueles com poder germinativo elevado e semelhante (MARCOS FILHO, 1999a).
Nesse sentido, um dos testes mais utilizados para a avaliação do vigor é o envelhecimento acelerado (VIEIRA; CARVALHO; SADER, 1994), sendo enfatizado por sua capacidade de proporcionar informações com alto grau de consistência (MARCOS FILHO, 1999a).

O envelhecimento acelerado ou envelhecimento precoce é um teste de vigor baseado na simulação de fatores ambientais adversos, temperatura e umidade relativa elevadas, os quais estão relacionados como causadores da deterioração das sementes (MARCOS FILHO, 1999b; TORRES; MARCOS FILHO, 2001). Sob essas condições, sementes com baixa qualidade fisiológica deterioram-se mais rapidamente do que sementes mais vigorosas, estabelecendo diferenças no potencial fisiológico das amostras avaliadas. Assim, lotes de sementes de alto vigor devem manter sua viabilidade quando submetidos a tais condições, enquanto que os de baixo vigor terão sua viabilidade reduzida (AOSA, 1983).

Originalmente o teste de envelhecimento acelerado foi desenvolvido com a finalidade de estimar a longevidade de sementes armazenadas, atualmente tem sido amplamente estudado com vistas à sua padronização (RODO; PANOBIANCO; MARCOS FILHO, 2000), tendo em vista que os processos de deterioração ocorridos neste teste são semelhantes aos que ocorrem no envelhecimento natural das sementes, porém, a uma velocidade acelerada (MARCOS FILHO, 1999b).

A interação entre temperatura e tempo de exposição das sementes às condições de envelhecimento são fatores importantes para a eficiência do teste e, para muitas espécies, essa interação ainda não foi estabelecida. O teste de envelhecimento acelerado pode ser conduzido com temperaturas entre 40 e $45^{\circ} \mathrm{C}$, sendo que recentemente a maioria dos trabalhos indica o uso de $41^{\circ} \mathrm{C}$ (MARCOS FILHO, 1999b). No entanto, Menezes e Nascimento (1988) constataram que a interação $37^{\circ} \mathrm{C} / 72 \mathrm{~h}$ foram os mais eficientes 
para avaliação do vigor de sementes de Pisum sativum L., enquanto Borges, Castro e Borges (1991) determinaram $50^{\circ} \mathrm{C} / 24 \mathrm{~h}$ para sementes de Cedrela fissilis L. Em sementes de Piptadenia communis Benth. houve redução significativa da sua viabilidade quando o envelhecimento acelerado foi realizado sob temperatura de $40^{\circ} \mathrm{C}$ (BORGES CASTRO; BORGES, 1992).

As condições indicadas para o teste de envelhecimento acelerado de sementes de Nepeta cataria e Oreganum vulgare L. foram $42^{\circ} \mathrm{C} / 48 \mathrm{~h}$ (BAGGIO et al., 2003), para soja $42^{\circ} \mathrm{C} / 48 \mathrm{~h}$ (DUTRA; VIEIRA, 2004), para sementes de Anadenanthera colubrina (Vell.) Brenan $40^{\circ} \mathrm{C} / 24 \mathrm{~h}$ (GARCIA; NOGUEIRA; ABREU, 2004), para Sebastiania commersoniana (Baill.) Smith \& Downs $45^{\circ} \mathrm{C} / 96 \mathrm{~h}$ (SANTOS; PAULA, 2007) e para sementes de Erythrina velutina Willd. $41^{\circ} \mathrm{C} / 72 \mathrm{~h}$ ou $45^{\circ} \mathrm{C} / 24 \mathrm{~h}$ (GUEDES et al., 2009).

Face à relevância de tais estudos e a escassez de informações neste aspecto com sementes de espécies florestais, este trabalho teve como objetivo de avaliar da qualidade fisiologia de sementes de jacarandá-da-bahia por meio do teste de envelhecimento acelerado.

\section{Material e Métodos}

A pesquisa foi conduzida no Laboratório de Análise de Sementes do Centro de Ciências Agrárias da Universidade Federal da Paraíba, em Areia - PB. Foram utilizadas sementes de Dalbergia nigra procedentes de matrizes localizadas no município de Areia - PB, as quais foram submetidas as seguintes determinações:

Teor de água - realizado com quatro amostras de 25 sementes colocadas em cápsulas de alumínio em estufa à $105^{\circ} \mathrm{C} \pm 3^{\circ} \mathrm{C}$ por 24 horas, cujos resultados foram expressos em porcentagem na base úmida (BRASIL, 2009).

Teste de germinação - $\mathrm{Na}$ avaliação da germinação foram utilizadas 100 sementes, as quais foram divididas em quatro repetições de 25 sementes. As sementes foram distribuídas no substrato papel toalha organizado na forma de rolo e umedecido com água destilada na quantidade equivalente a três vezes o seu peso seco. Em seguida foram colocadas em germinador tipo Biochemical Oxigen Demand (B.O.D.) regulado para o regime de temperatura constante de $25^{\circ} \mathrm{C}$, com fotoperíodo de oito horas, utilizando lâmpadas fluorescentes tipo luz do dia $(4 \times 20 \mathrm{~W})$. As contagens foram realizadas durante 15 dias, considerando-se como sementes germinadas aquelas que emitiram a raiz primária e o parte aérea normais, sendo o resultado expresso em porcentagem.

Emergência de plântulas em campo - Na avaliação da emergência foram utilizadas 100 sementes, as quais foram divididas em quatro repetições de 25 cada e semeadas a $2,0 \mathrm{~cm}$ de profundidade em sulcos de 1,0 $\mathrm{m}$ de comprimento e distanciadas $10 \mathrm{~cm}$ entre si. Realizou-se contagens diárias do 4o até 210 dia após a semeadura, sendo consideradas emergidas as plântulas com os cotilédones acima do solo. Os resultados foram expressos em porcentagem (NAKAGAWA, 1999).

Teste de envelhecimento acelerado - Ensaios de adequação da metodologia do envelhecimento acelerado foram realizados, com duas temperaturas de $41^{\circ} \mathrm{C}$ e $45^{\circ} \mathrm{C}$, combinados com diferentes tempos de exposição das sementes ao estresse e comparandose os resultados à emergência de plântulas em campo e condutividade elétrica, para se obter as recomendações adequadas para validar o teste. Para a condução do teste de envelhecimento acelerado utilizou-se o procedimento proposto pela AOSA (1983) e descrito por Marcos Filho (1999b). Foram distribuídas uniformemente 100 sementes sobre uma tela de alumínio, fixada em caixa plástica do tipo "gerbox", contendo $40 \mathrm{~mL}$ de água. As caixas, com as sementes, foram fechadas e mantidas a 41 e $45^{\circ} \mathrm{C}$ (100\% UR) por 24, 48 e 72 e 96 horas. Foi testado o período zero que corresponde à testemunha. Ao término de cada período as sementes foram submetidas ao teste de germinação e a porcentagem 
de plântulas normais foi computada no final do teste (15 dias). Determinou-se também o teor de água das sementes antes e após os diferentes períodos de envelhecimento, visando avaliar a uniformidade das condições do teste.

Teste de condutividade elétrica - Foram empregadas quatro repetições de 50 sementes, submetidas a cada temperatura $\left(41 \mathrm{e} 45^{\circ} \mathrm{C}\right)$ e período de exposição do envelhecimento $(0,24,48,72$ e $96 \mathrm{~h}$ ), as quais foram pesadas, colocadas em becker com $75 \mathrm{~mL}$ de água destilada por 24 horas sob $25^{\circ} \mathrm{C}$ (MARQUES; PAULA; RODRIGUES, 2002). Passado esse período de embebição as leituras foram realizadas com condutivímetro, cujos valores determinados foram divididos pela massa relativa às 50 sementes e expressos em $\mu$ mho. $\mathrm{cm}^{-1} \cdot \mathrm{g}^{-1}$.

Análise estatística - A análise estatística dos dados foi realizada segundo o delineamento experimental inteiramente ao acaso. Para o teste de envelhecimento acelerado os tratamentos foram dispostos em esquema fatorial $2 \times 5$ (temperaturas e períodos de envelhecimento), em quatro repetições. Os dados foram submetidos à análise de variância e de regressão polinomial.

\section{Resultados e Discussão}

Pelos resultados do teste de emergência de plântulas em campo observou-se elevada qualidade fisiológica das sementes de Dalbergia nigra, com porcentual de emergência de $84 \%$. Este teste é considerado o melhor indicativo para inferir sobre o vigor de sementes, pois na sua execução devem ser utilizadas condições que simulem aquelas que as sementes estarão sujeitas por ocasião da semeadura em campo. Durante o período de condução do teste registrou-se temperatura média de $23^{\circ} \mathrm{C}$ e umidade relativa média de $87 \%$.

Os resultados relativos ao teor de água inicial das sementes e aqueles atingidos após a realização dos tratamentos de envelhecimento acelerado estão apresentados na (Figura 1). No início do teste o teor de água das sementes variou de 7,55 a $8,70 \%$ sugerindo que o mesmo se encontrava na faixa indicada para realização do teste, uma vez que diferenças de 1 a $2 \%$ no teor de água entre amostras não são comprometedoras. Entretanto, discrepâncias acentuadas podem provocar alterações na velocidade de umedecimento das sementes durante o tratamento de envelhecimento e determinar diferenças na intensidade de deterioração (MARCOS FILHO, 1999b).

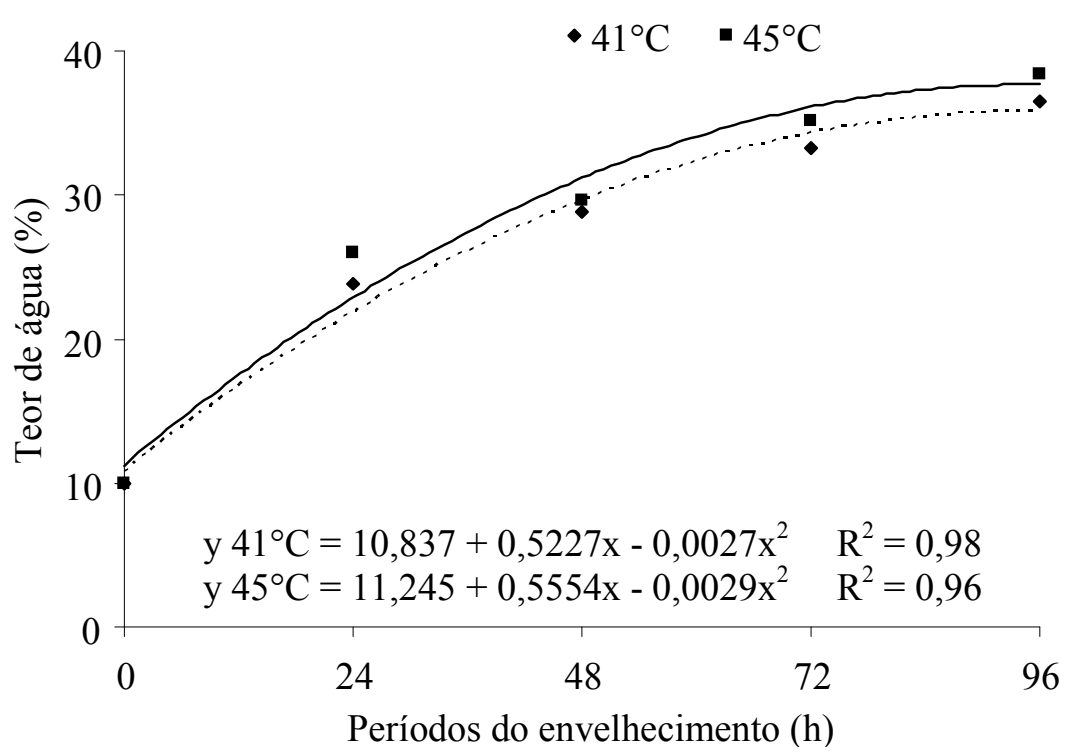

Figura 1. Teor de água de sementes de Dalbergia nigra (Vell.) Fr. All., antes e após o envelhecimento acelerado. 
Ao longo do envelhecimento constatou-se que as sementes absorveram água, atingindo valores superiores a $30 \%$ em ambas as temperaturas (41 e $45^{\circ} \mathrm{C}$ ) após 96 horas. De acordo com Carvalho e Nakagawa (2000), incrementos nos teores de água favorecem o aumento da temperatura na semente, em decorrência dos processos respiratórios e da maior atividade de microorganismos. Assim, o aumento da exposição ao envelhecimento acelerado pode ter proporcionado maior incremento no teor de água das sementes condicionadas, aliada a temperatura elevada $\left(45^{\circ} \mathrm{C}\right)$ imposta pelo teste, resultando em processo de deterioração mais acelerado dessas sementes em relação aquelas não submetidas ao envelhecimento ou envelhecidas em temperaturas menores $\left(41^{\circ} \mathrm{C}\right)$.

Em todas as avaliações realizadas ao final do teste não se verificou variações acentuadas do teor de água das sementes, sugerindo uniformidade na condução do envelhecimento acelerado, uma vez que, variações entre 3 e 4\% entre as amostras são toleráveis (MARCOS FILHO, 1999b).

$\mathrm{Na}$ (Figura 2) são apresentados os resultados da avaliação da qualidade fisiológica das sementes de D. nigra pelo teste de germinação. Observouse um decréscimo significativo no percentual de plântulas normais à medida que as sementes foram envelhecidas. No entanto, quando as sementes foram submetidas à temperatura de $41^{\circ} \mathrm{C}$, não foram observadas diferenças significativas no tempo de 24 horas, em relação ao controle (0 hora), mas estes foram superiores aos demais, indicando haver uma redução drástica da qualidade fisiológica das sementes a partir de 72 horas de envelhecimento. Resultados semelhantes foram verificados para sementes de Ocimum gratissimum L. (LIMA; ATHANÁZIO; BELletTINI, 2006), Pimpinella asinum L. (TORRES, 2004), Cucumis anguria L (TORRES; MARCOS FILHO, 2001) e Erythrina velutina Willd (GUEDES et al., 2009).

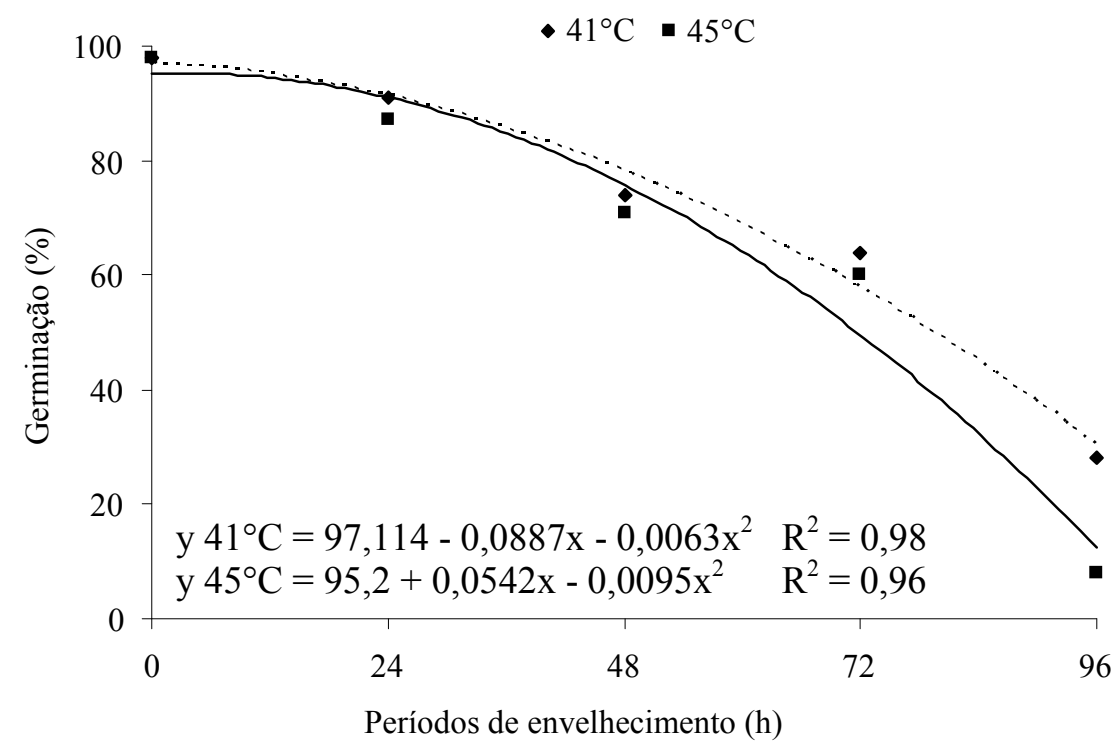

Figura 2. Porcentagem de germinação de sementes de Dalbergia nigra (Vell.) Fr. All., antes e após o envelhecimento acelerado.

Quando se utilizou a temperatura de $45^{\circ} \mathrm{C}$ houve drástica redução nos valores de germinação após 72 horas, acentuando-se com o aumento do período de exposição ao envelhecimento, especificamente às 96 horas, atingindo apenas $8 \%$ de germinação.
Provavelmente esta redução esteja associada ao processo de deterioração das sementes, quando submetidas às condições de altas temperaturas e alta umidade (Figuras 1 e 2).

A elevação da temperatura no teste de 
envelhecimento promove efeitos mais drásticos na germinação do que o prolongamento do período de exposição ao envelhecimento (TOMES; TEKRONY; EGLI, 1988). Resultados semelhantes foram observados por Borges, Castro e Borges (1990) com sementes de Cedrela fissilis L., Guedes et al. (2009) com sementes de Erythrina velutina Willd.

Oenvelhecimentodesementesocasionaalterações metabólicas durante o processo germinativo, incluindo o metabolismo respiratório e alteração na estrutura das membranas (BASAJAVARAJAPPA; BASAJAVARAJAPPA; SHETY; PRAKASH, 1991), síntese de proteínas, ácidos nucléicos e metabolismo do DNA (VÁZQUEZ; MONTIEL; VÁZQUEZ-RAMOS, 1991), além de proporcionar atraso no processo germinativo, menor crescimento do embrião e suscetibilidade a estresses ambientais, levando eventualmente a perda da viabilidade.

À medida que as sementes foram envelhecidas houve uma redução no seu vigor determinado pelo teste de condutividade elétrica (Figura 3), pelo qual se detectou um aumento significativo na quantidade de lixiviados para as sementes submetidas ao envelhecimento em ambas as temperaturas $\left(41^{\circ} \mathrm{C}\right.$ e $45^{\circ} \mathrm{C}$ ), sendo mais intenso quando as sementes foram submetidas à temperatura de $45^{\circ} \mathrm{C}$.

Com a desestruturação do sistema de membranas das organelas celulares, evidenciado pelo aumento progressivo na quantidade de lixiviados, as sementes tornam-se mais susceptíveis aos efeitos deletérios do O2, que promove a oxidação dos compostos e, também à ação de enzimas, que segundo Bewley e Black, (1994) fazem com que as reservas sejam consumidas mais rapidamente. A redução gradativa da viabilidade e do vigor das sementes, promovida pelas condições estressantes durante o envelhecimento acelerado pode ser observada pelas características avaliadas. Isto se deve a um maior consumo das reservas, decorrente da acelerada atividade metabólica nestas condições.

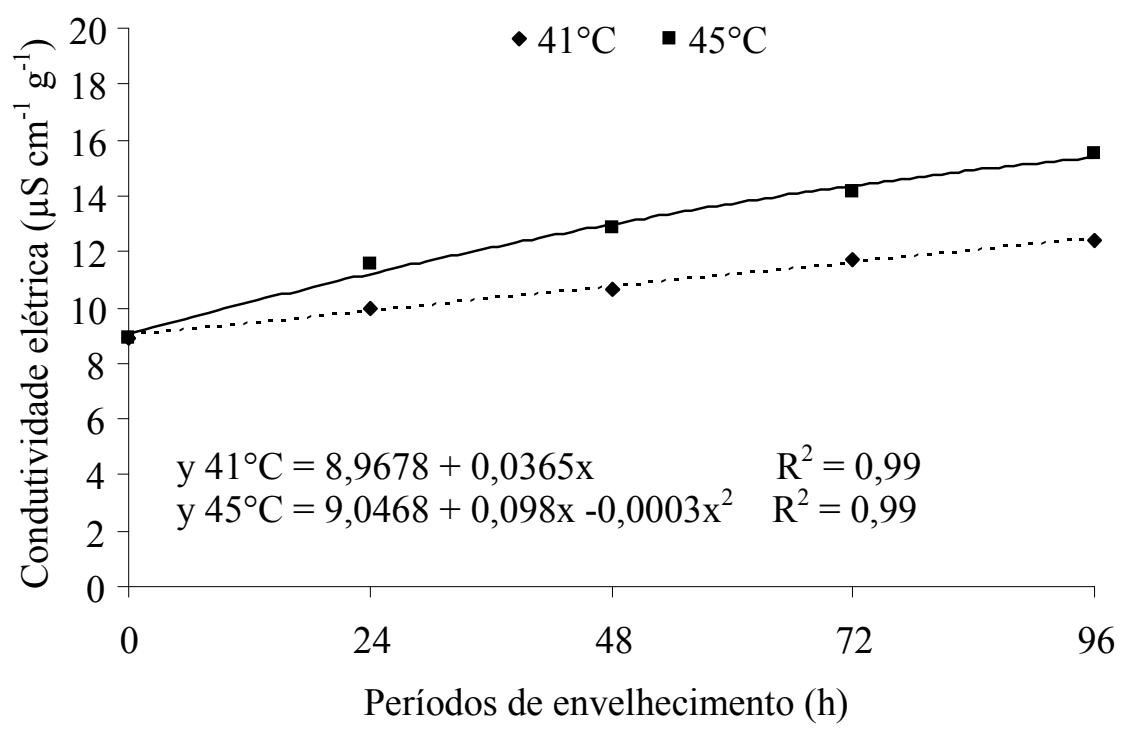

Figura 3. Condutividade elétrica $\left(\mu \mathrm{S} \mathrm{cm}^{-1} \mathrm{~g}^{-1}\right)$ da solução de embebição de sementes de Dalbergia nigra (Vell.) Fr. All. antes e após o envelhecimento acelerado.

Como se verificou nesta pesquisa, a perda da viabilidade das sementes é resultante de eventos metabólicos importantes, sendo a deterioração manifestadaporvários meios, os quais podemimpedir a germinação (DESAI; KOTECHA; SALUNKE, 1997). Quando colocadas em condições favoráveis 
para germinação, nas sementes envelhecidas há menor atividade das enzimas hidrolíticas, as quais são responsáveis pela mobilização das reservas para o crescimento do embrião, do que as sementes não envelhecidas (FERREIRA et al., 2004).

Resultados semelhantes aos encontrados neste trabalho foram observados por Ferreira et al. (2004) com sementes de Copaifera langsdorffi. Borges, Castro e Borges (1992) e Fanti (1996) verificaram que sementes de Piptadenia communis Benth. e de Adenatnhera pavonina L., respectivamente, reduziram significativamente a sua viabilidade e vigor quando submetidas ao envelhecimento acelerado, em condições de $45^{\circ} \mathrm{C}$ e $100 \%$ de umidade relativa, em relação ao controle.

Perez e Nassif (1998) constataram que o mesmo processo ocorreu com sementes de Prosopis juliflora $\mathrm{Sw}$ DC. Os autores consideraram que, quanto maior o tempo de envelhecimento menor a viabilidade e o vigor de sementes das espécies estudadas. Guedes et al. (2009) aplicaram o teste de condutividade elétrica em sementes de Erythrina velutina Willd. submetidas ao envelhecimento acelerado, e registraram que o vigor das sementes de foi bastante afetado durante o envelhecimento acelerado, constatado pelo aumento na quantidade de lixiviados liberados das sementes. Com as sementes de D. nigra verificou-se comportamento similar, no presente trabalho.

\section{Conclusões}

O envelhecimento em ambas as temperaturas $\left(41^{\circ} \mathrm{C} \mathrm{e} 45^{\circ} \mathrm{C}\right)$ a partir de 72 horas, afeta a qualidade fisiológica de sementes de Dalbergia nigra (Vell.) Fr. All., promovendo redução da viabilidade e do vigor.

O vigor das sementes é afetado durante o envelhecimento, constatado pelo aumento na quantidade de lixiviados, observado pelo teste de condutividade elétrica.

\section{Referências}

ASSOCIATION OF OFFICIAL SEED ANALYSTS - AOSA. Seed vigor testing handbook. East Lansing, 1983. 88 p. (Contribution, 32).

BAGGIO, L.; LIMA, C. B.; SATO, O.; BUENO, J. T.; KOSTETZER, K.; LEITE, L. L.; BERTHI, D.; SILVA, M. Influência do número de horas de envelhecimento acelerado sobre as sementes de Nepeta cataria e Oreganum vulgare. Informativo ABRATES, Curitiba, v. 13, n. 3, p. 416, 2003.

BASAJAVARAJAPPA, B. S.; SHETY, S. H.; PRAKASH, H. S. Membrane deterioration and other biochemical changes, associated with accelerated aging of maize seeds. Seeds Science and Technology, Zurich, v. 2, n. 2, p. 279-286, 1991.

BEWLEY, J. D.; BLACK, M. Seeds: physiology of development and germination. 2. ed. New York: Plenum Press, 1994. 455 p.

BORGES, E. E. L.; CASTRO, J. L. D.; BORGES, R. C. G. Alterações fisiológicas em sementes de jacaré (Piptadenia communis) submetidas ao envelhecimento precoce. Revista Brasileira de Sementes, Brasília, v. 14, n. 1, p. 9-12, 1992.

Avaliação fisiológica de sementes de cedro submetidas ao envelhecimento precoce. In: SIMPÓSIO BRASILEIRO DE TECNOLOGIA DE SEMENTES FLORESTAIS, 2., 1989, São Paulo. Anais.... Instituto Florestal de São Paulo, 1991. p. 28.

Avaliação fisiológica de sementes de cedro submetidas ao envelhecimento precoce. Revista Brasileira de Sementes, Brasília, v. 12, n. 1, p. 56-62, 1990.

BRASIL. Ministério da Agricultura, Pecuária e Abastecimento. Regras para análise de sementes. Brasília, DF: Mapa/ACS, 2009. 399 p.

CARVALHO, N. M.; NAKAGAWA, J. Sementes: ciência, tecnologia e produção. 4. ed. Jaboticabal: Funep, 2000. 588 p.

CARVALHO, P. E. R. Espécies florestais brasileiras: recomendações silviculturais, potencialidades e uso da madeira. Colombo: Embrapa/CNPF; Brasília: Embrapa/ SPI, 1994. $638 \mathrm{p}$.

DESAI, B. B.; KOTECHA, P. M.; SALUNKE, D. K. Seeds handbook: biology, production, processing and storage. New York: Marcel Dekker, 1997. 627 p.

DUTRA, A. S.; VIEIRA, R. D. Envelhecimento acelerado como teste de vigor para sementes de milho e soja. Ciência Rural, Santa Maria, v. 34, n. 3, p. 715-721, 
2004.

FANTI, S. C. Comportamento germinativo sob condições de estresse e influência do sombreamento artificial e adubação química na produção de mudas de Adenanthera pavonina L. 1996. Dissertação (Mestrado em Ecologia e Recursos Naturais) - Universidade Federal de São Carlos, São Carlos, SP.

FERREIRA, R. A.; OLIVEIRA, L. M.; CARVALHO, D.; OLIVEIRA, A. F.; GEMAQUE, R. C. R. Qualidade fisiológica de sementes de Copaifera langsdorffii Desf. (Leguminosae - Caesalpinioideae) envelhecidas artificialmente. Revista Ciência Agronômica, Fortaleza, v. 35, n. 1, p. 82-86 2004.

GARCIA, L. C.; NOGUEIRA, A. C.; ABREU, D. C. A. Influência do envelhecimento acelerado no vigor de sementes de Anadenanthera colubrina (Vellozo) Brenan - Mimosaceae. Ciência Florestal, Santa Maria, v. 14, n. 1, p. 85-90, 2004.

GUEDES, R. S.; ALVES, E. U.; GONÇALVES, E. P.; VIANA, J. S.; BRUNO, R. L. A.; COLARES, P. N. Q. Resposta fisiológica de sementes de Erythrina velutina Willd. ao envelhecimento acelerado. Semina: Ciências Agrárias, Londrina, v. 30, n. 2, p. 323-330, 2009.

GONÇALVES, E. P.; PAULA, R. C.; DEMATTÊ, M. E. S. P.; SILVA, M. A. D. Potencial fisiológico de sementes de mutambo (Guazuma ulmifolia Lam.) em diferentes procedências. Revista Caatinga, Mossoró, v. 22, n. 2, p. 218-222, 2009.

IBAMA. Instituto Brasileiro de Meio Ambiente e dos Recursos Naturais Renováveis. Lista oficial de espécies da flora brasileira ameaçada de extinção. Portaria $\mathrm{n}^{\circ} .37-\mathrm{N}$ de 3 de abril de 1992. Disponível em: <http:// www.ibama.gov.br>. Acesso em: 10 dez. 2008.

LIMA, C. B.; ATHANÁZIO, J. C.; BELLETTINI, N. M. T. Germinação e vigor de sementes de alfavaca-cravo (Ocimum gratissimum L.) submetidas ao envelhecimento acelerado. Semina: Ciências Agrárias, Londrina, v. 27, n. 2, p. 159-170, 2006.

LORENZI, H. Árvores brasileiras: manual de identificação de plantas arbóreas nativas do Brasil. São Paulo: Plantarum, 2002. 368 p.

MARCOS FILHO, J. Teste de envelhecimento acelerado. In: KRZYZANOWSKI, F. C.; VIEIRA, R. D.; FRANÇA NETO, J. B. (Ed.). Vigor de sementes: conceitos e testes. Londrina: ABRATES, 1999b. cap. 3, p. 1-24.

Testes de vigor: importância e utilização. In: KRZYZANOWSKI, F. C.; VIEIRA, R. D.; FRANÇA NETO, J. B. (Ed.). Vigor de sementes: conceitos e testes. Londrina: ABRATES, cap. 1, p. 1-21, 1999a.
MARQUES, M. A.; PAULA, R. C.; RODRIGUES, T. J. D. Efeito do número de sementes e do volume de água na condutividade elétrica de sementes de Dalbergia nigra (Vell.) Fr.All. ex Benth. Revista Brasileira de Sementes, Londrina, v. 24, n. 1, p. 254-262, 2002.

MENEZES, J. E.; NASCIMENTO, W. M. Teste de envelhecimento precoce em sementes de ervilha (Pisium sativum L.). Horticultura Brasileira, Brasília, v. 6, n. 1, p. 63, 1988. Resumos.

NAKAGAWA, J. Testes de vigor baseados no desempenho das plântulas. In: KRZYZANOSKI, F. C.; VIEIRA, R. D.; FRANÇA NETO, J. B. (Ed.). Vigor de sementes: conceitos e testes. Londrina: ABRATES, 1999. p. 21-24.

PEREZ, S. C. J. G. A.; NASSIF, S. M. L. Efeitos do envelhecimento precoce, polietilenoglicol e substratos na viabilidade e vigor de sementes de algarobeira. Pesquisa Agropecuária Brasileira, Brasília, v. 33, n. 12, p. 2055 2064, 1998.

RODO, A. B.; PANOBIANCO, M.; MARCOS FILHO, J. Metodologia alternativa do teste de envelhecimento acelerado para sementes de cenoura. Scientia Agricola, Piracicaba, v. 57, n. 2, p. 289-292, 2000.

SANTOS, S. R. G.; PAULA, R. C. Teste de envelhecimento acelerado para a avaliação do vigor de lotes de sementes de Sebastiania commersoniana (Baill.) Smith \& Downs (branquilho) - Euphorbiaceae. Revista Instituto Florestal, São Paulo, v. 19, n. 1, p. 1-12, 2007.

TOMES, L. J.; TEKRONY, D. M.; EGLI, D. B. Factors influencing the tray accelerated aging test for soybean seed. Journal of Seed Technology, East Lansing, v. 12, n. 1, p. 24-35, 1988.

TORRES, S. B. Teste de envelhecimento acelerado em sementes de erva-doce. Revista Brasileira de Sementes, Brasília, v. 26, n. 2, p. 20-24, 2004.

TORRES, S. B.; MARCOS FILHO, J. Teste de envelhecimento acelerado em sementes de maxixe (Cucumis anguria L.). Revista Brasileira de Sementes, Brasília, v. 23, n. 2, p. 108-112, 2001.

VÁZQUEZ, E.; MONTIEL, F.; VÁZQUEZ-RAMOS, J. M. DNA ligase activity in deteriorated maize axes during germination: a model relating defects in DNA metabolism in seeds to loss of germinability. Seed Science Research, Wallingford, v. 1, n. 2, p. 269-273, 1991.

VIEIRA, R. D.; CARVALHO, N. M.; SADER, R. Testes de vigor e suas possibilidades de uso. In: VIEIRA, R. D.; CARVALHO, N. M. (Ed.). Teste de vigor em sementes. Jaboticabal: FUNEP, 1994. p. 31-47. 